\title{
Building bone mass through exercise: could less be more?
}

\section{T S Gross, S Srinivasan}

\section{Insertion of a rest interval between loading events greatly amplifies the response of bone to loading}

elderly populations has been the incomplete elucidation of specific bone mechanotransduction pathways. In vivo studies of bone adaptation have clearly confirmed that bone is responsive to a variety of specific aspects of mechanical loading such as magnitude and serial bouts of activity. ${ }^{67}$ Although the benefit of increased loading or activity eventually plateaus, few would argue that the greater the stimulus, the bigger the response of the tissue. Substantial progress has been made in studying the molecular events underlying this pathway, including identification of numerous second messengers, transcription factors, and signal transduction genes, the regulation of which is rapidly altered in various bone cells by mechanical stimuli. However, mechanotransduction within bone remains a largely unresolved area of research.

\section{"...high magnitude loading is not practical for those seniors acutely in need of bone augmentation"}

The most efficacious exercise interventions have exposed young developing skeletons to dynamic impact loads such as those induced by jumping. ${ }^{3}$ The success of such a regimen stems, in part, from the enhanced ability of the developing skeleton to respond to mechanical stimuli compared with an aged skeleton $^{4}$ and, we would argue, the intermittent nature of activities such as jumping. However, although impact exercise interventions may serve to augment peak skeletal strength and thereby serve as a potential prophylaxis for future osteopenias, high magnitude loading is not practical for those seniors acutely in need of bone augmentation. Exercise that is accessible for this population, such as the relatively mild skeletal loading that might be generated by walking or resistance exercise, is not perceived as a stimulus for bone formation. $^{5}$

It is quite likely that a primary contributor to the poor efficacy of exercise interventions in adult and tiveness of rest insertion lies with its contradiction of the "bigger the stimulus, the bigger the response" principle. The potential mechanisms underlying the effectiveness of rest insertion are numerous and may range from simple amplification of standard pathways to activation of alternative signalling pathways. Given the difficulty associated with defining specific biochemical mechanotransduction pathways in vivo, we have begun to explore this question from a different perspective, using approaches of complex adaptive system biology to identify particular aspects of cellular activation that may explain the effectiveness of rest inserted loading. ${ }^{11}$ Complex adaptive (biological) systems are characterised by internal heterogeneity, hierarchical structure, non-linear interactions, and high degrees of connectivity within and between parts of the system. Approaches used to analyse such systems are typically inductive and are premised on the observation that local interactions (such as generation and/or perception of signalling molecules by adjacent osteocytes) are capable of inducing emergent system behaviours (such as osteoblast activity days or weeks after the loading event).

In this context, we have examined how rest inserted stimuli may be perceived by osteocytes by an agent based modelling technique that is uniquely suited to studying counterintuitive and emergent phenomena. The model predicted that inserting a rest interval between load cycles enhances and sustains signalling activity within osteocytic networks. This augmented signalling arose by a combination of more efficiently exploiting the dynamics of second messenger generation and depletion and by augmenting intercellular communication within the osteocyte network. Thus the model suggests that the osteogenic potency of rest inserted stimuli emerges from real time activity induced within the cellular syncytium of the bone during the brief time-that is, seconds-that the skeleton is subjected to loading. The agent based modelling approach also holds potential for expansion to examine transduction of specific signalling molecules-for example, $\mathrm{Ca}^{2+}$ or ATP-or enhanced diffusion of these factors as might be achieved by rest inserted loading. Pending further studies and experimental validation, it appears that biological mechanisms of rest insertion may lie at the level of altering how osteocytes behave within the context of their local cellular neighbourhood.

The specific signalling pathways underlying the effectiveness of rest insertion may prove elusive. However, 
it is our belief that this strategy may yield positive clinical results without exact knowledge of its mechanism. In this context, our complexity based approach may provide a tool to optimise rest inserted loading waveforms and to design strategies that compensate for potential variations associated with factors such as age or genetic background. With future optimisation, rest insertion holds the potential to enable more bone accretion with less exercise compared with current repetitive loading strategies. Whereas cyclic aerobic exercise undoubtedly confers numerous physiological and psychological benefits beyond the skeleton, a rest inserted exercise regimen, in our view, holds greatly enhanced potential for utilisation in a couch potato era of substantially diminished physical fitness.

Br J Sports Med 2006;40:2-3.

doi: 10.1136/bjsm.2004.016972

\section{Authors' affiliations \\ T S Gross, S Srinivasan, University of \\ Washington, Seattle, WA, USA}

Correspondence to: Dr Gross, Department of Orthopaedics and Sports Medicine, University of Washington, 1959 NE Pacific St, Box 356500, Seattle, WA 98195-6500, USA; tgross@u.washington.edu

Accepted 12 July 2005
Competing interests: none declared

\section{REFERENCES}

1 Leblanc AD, Schneider VS, Evans HJ, et al. Bone mineral loss and recovery after 17 weeks of bed rest. J Bone Miner Res 1990;5:843-50.

2 Haapasalo H, Kannus P, Sievanen II, et al. Longterm unilateral loading and bone mineral density and content in female squash players. Calcif Tiss Int 1994;54:29-55.

3 Petit MA, McKay HA, MacKelvie KJ, et al. A randomized school-based jumping intervention confers site and maturity-specific benefits on bone structural properties in girls: a hip structural analysis study. J Bone Miner Res 2002;17:363-72.

4 Rubin CT, Bain SD, McLeod KJ. Suppression of the osteogenic response in the aging skeleton. Calcif Tissue Int 1992;50:306-13.

5 Pruitt LA, Taaffe DR, Marcus R. Effects of a oneyear high-intensity versus low-intensity resistance training program on bone mineral density in older women. J Bone Miner Res 1995; 10:1788-95

6 Rubin CT, Lanyon LE. Regulation of bone mass by mechanical strain magnitude. Calcif Tissue Int 1985;37:41 1-17.

7 Robling AG, Burr DB, Turner $\mathrm{CH}$. Partitioning a daily mechanical stimulus into discrete loading bouts improves the osteogenic response to loading. J Bone Miner Res 2000;15:1596-602.

8 LaMothe JM, Zernicke RF. Rest insertion combined with high-frequency loading enhances osteogenesis. J Appl Physiol 2004;96:1788-93.

9 Lee KC, Jessop H, Suswillo R, et al. The adaptive response of bone to mechanical loading in female transgenic mice is deficient in the absence of oestrogen receptor-alpha and -beta. J Endocrinol 2004; 182:193-201.

10 Srinivasan S, Agans SC, King KA, et al. Enabling bone formation in the aged skeleton via restinserted mechanical loading. Bone 2003;33:946-55.
11 Gross TS, Poliachik SL, Ausk BJ, et al. Why rest stimulates bone formation: a hypothesis based on complex adaptive phenomenon. Exerc Sport Sci Rev 2004;32:9-13.

\section{COMMENTARY}

Dynamic mechanical loading has been shown to actively influence the adaptive activities of bone in many animal studies and clinical observations. This report reviews recent studies on rest insertion between loading events, which amplifies the response of bone to loading, and suggests that the adaptation of bone to mechanical loading may be triggered by specific mechanical stimuli, but not necessarily correlate with the "magnitude" per se. The authors further develop a model and examine the cellular signalling pathway to predict the signalling activity in the osteocytic networks. This is an interesting approach to explaining how bone is sensitive to novel mechanical intervention at the cellular level. The high anabolic response to rest insertion of loading may also be supported by the mechanotransduction pathway, in which rest insertion would improve the fluid saturation caused by continuous loading and enhance perfusion in bone. This work provides valuable insight into the mechanism of bone adaptation and potential design of therapeutic strategies for clinical applications. SUNY at Stony Brook, New York, NY, USA; yi-xian.qin@sunysb.edu

\section{Benefits of exercise therapy for chronic diseases}

\section{U M Kujala}

\section{Evidence on the benefits of exercise therapy for chronic diseases based on randomised controlled trials is accumulating}

$\mathrm{R}$ egular physical activity is one means of decreasing disability and increasing the number of independently living elderly people, as well as decreasing the costs of the healthcare system. On the basis of a recent review of the results of randomised controlled trials (RCTs), there is accumulating evidence that, in patients with chronic disease, exercise therapy is effective in increasing fitness and correcting some risk factors for the development of disease complications. ${ }^{1}$

\section{FROM PREVENTION TO TREATMENT}

Traditionally physical activity has been regarded as a powerful tool in the prevention of certain chronic diseases, even though this has been confirmed in only a very few cases by RCTs. ${ }^{2}$ When the strength of evidence for the use of exercise in health care is evaluated, data from epidemiological observational follow ups, studies on the mechanisms of disease, and controlled clinical trials are used. Observational follow up studies can be biased for many reasons, such as genetic selection bias and inability to control for all confounding lifestyle factors. ${ }^{3}$ However, it has been widely accepted that an epidemiological observational study with supportive data from studies on disease mechanisms provides enough evidence for exercise recommendations in disease prevention. Conclusive evidence for the benefits of exercise in the treatment of patients with chronic disease using the limited resources of the healthcare system should optimally be based on well designed RCTs. ${ }^{1}$ Recently, the number of RCTs evaluating the effects of physical exercise therapy for specific diseases has increased substantially, allowing disease specific systematic reviews including meta-analyses.

\section{MAIN FINDINGS OF SYSTEMATIC REVIEWS BASED ON RCTS}

The most consistent finding of the studies is that exercise capacity or muscle strength can be improved in patients with different diseases without having detrimental effects on disease progression. ${ }^{1}$ Severe complications in 
the exercise trials were rare. In some diseases, such as osteoarthritis, pain symptoms may also be reduced. Most RCTs are too short to document disease progression. Studies on patients with coronary heart disease, ${ }^{4}$ as well as studies on patients with heart failure, ${ }^{5}$ show that exercise groups have a somewhat reduced all-cause mortality. The clinically very significant findings include that exercise therapy has beneficial effects on all metabolic syndrome components and is highly beneficial for patients with type 2 diabetes mellitus. ${ }^{16}$

\section{STUDY QUALITY IS IMPORTANT}

Before the results are considered, the methodological quality of the individual RCTs should be critically analysed. ${ }^{78}$ Biased results from poorly designed and reported trials can mislead decision making. It should be taken into account that exercise trials cannot usually be properly blinded, which may lessen the reliability of the results. In addition to other quality criteria, we have to keep in mind that generalisability may be a problem as some RCTs include patients that are not representative of the general population of patients with regard to age and coexisting diseases. This is typically seen in RCTs on coronary heart disease and heart failure.

The fact that most trials are of short duration means that some benefits, such as increases in physical fitness, are reached within weeks or months. However, specific RCTs are usually too short to provide conclusive evidence on the effects of exercise therapy on the true progression of disease. RCTs on the effects of exercise on lipid risk factors, blood pressure levels, and glucose homoeostasis, ${ }^{6}$ as well as sporadic long term follow ups of disease progression, ${ }^{45}$ support the conclusion that exercise therapy may have a beneficial effect on the long term progression of specific diseases. ${ }^{1}$ However, there is a need for RCTs with long term follow ups, including documentation, of such outcomes as survival rate, rate of hospital admission, and healthcare costs.

\section{CLINICAL PRESCRIPTION OF EXERCISE}

Doctors prescribing exercise therapy have to know the basics of exercise physiology and training principles. Also, tailoring of a programme depends on the disease and its stage, the baseline fitness level of the patient, and the goals of the programme set together with the patient.

The available RCTs include a large variety of effective training programmes. Most patients seem to benefit from low to moderate intensity aerobic exercise. Detailed conclusions on the doseresponse of exercise therapy in the treatment of specific diseases cannot be drawn from the available RCTs. We have to remember that the beneficial results of exercise therapies for patients with chronic disease shown by RCTs are based on carefully planned and followed exercise interventions in patients whose clinical status has first been examined to take into account possible risks. Unlike the prevention of disease in young healthy people, the therapeutic range of physical activity for patients with chronic disease may be limited. In exercise therapy, long term adherence is a general problem. Exercise consultations face to face or by telephone can be used to maintain high physical activity levels. Also, whereas we look for evidence of the benefits of exercise therapy from RCTs specifically investigating the effects of exercise, in clinical work we have to bear in mind that correction of other modifiable risk factors such as $\operatorname{diet}^{10}$ and smoking ${ }^{3}$ are also important, as is the optimal medication.

Br J Sports Med 2006;40:3-4.

doi: 10.1136/bjsm.2005.021717

Correspondence to: Dr Kujala, Department of Health Sciences, University of Jyvaskyla, PO Box 35, Jyvaskyla, Finland; urho.kujala@sport. iyu.fi

Accepted 1 August 2005

Competing interests: none declared

\section{REFERENCES}

1 Kujala UM. Evidence for exercise therapy in the treatment of chronic disease based on at least three randomized controlled trials: summary of published systematic reviews. Scand J Med Sci Sports 2004 $14 \cdot 339-45$

2 Kesäniemi YA, Danforth $E$, Jensen MD, et al. Dose-response issues concerning physical activity and health: an evidence-based symposium. Med Sci Sports Exerc 2001;33:S351-8.

3 Kujala UM, Kaprio J, Koskenvuo M. Modifiable risk factors as predictors of all-cause-mortality: the roles of genetics and childhood environment. Am J Epidemiol 2002;156:985-93.

4 Taylor RS, Brown A, Ebrahim S, et al. Exercise-based rehabilitation for patients with coronary heart disease: systematic review and meta-analysis of randomized controlled trials. Am J Med 2004;1 16:682-92.

5 Smart N, Marwick TH. Exercise training for patients with heart failure: a systematic review of factors that improve mortality and morbidity. Am J Med 2004; 1 16:693-706.

6 Boule NG, Haddad E, Kenny GP, et al. Effect of exercise on glycemic control and body mass in type 2 diabetes mellitus. A meta-analysis of controlled clinical trials. JAMA 2001;286:1218-27.

7 Altman DG, Schulz KF, Moher D, et al. The revised CONSORT statement for reporting randomized trials: explanation and elaboration. Ann Intern Med 2001; 134:663-94.

8 Van Tulder M, Furlan A, Bombardier C, et al. Updated method guidelines for systematic reviews in the Cochrane Collaboration Back Review Group. Spine 2003;28:1290-9.

9 Kirk A, Mutrie N, Maclntyre P, et al. Increasing physical activity in people with type 2 diabetes. Diabetes Care 2003;26:1186-92.

10 Leon AS, Sanchez OA. Response of blood lipids to exercise alone or combined with dietary intervention. Med Sci Sports Exerc 2001;33:S502-15.

\section{Gene therapy in sport}

\section{R J Trent, I E Alexander}

\section{The potential benefits of gene therapy for sports injuries are counterbalanced by the potential for gene doping}

$\mathrm{H}$ uman gene therapy involves the insertion of DNA (or RNA) into somatic cells to produce a therapeutic effect. Gene therapy was first envisaged as an approach to treating genetic disorders. In this scenario, missing or mutant genes could be replaced or repaired. Today, gene therapy has broader applications, with trials covering many clinical problems including genetic diseases, cancer, infections such as HIV, and degenerative diseases.
The transfer of genetic material into cells can be undertaken in many ways, most commonly using a viral vector. For this, viruses are genetically engineered to remove infectious potential while retaining the capacity to carry a therapeutic gene(s) into selected target cells. The inserted sequences can encode a missing or mutant product as might occur in the case of cancer, or alternatively could be used to inhibit a foreign protein as would be found in HIV infection. Viral vectors have been derived from a number of different viruses. Some, such as the adenovirus, are associated with relatively mild human infections, whereas others are associated with more serious disease, for example HIV. Certain viral properties 
Table 1 Human gene therapy studies with potential application to sport

\begin{tabular}{ll}
\hline Model & Status \\
\hline Muscular dystrophy & $\begin{array}{l}\text { Using animals with muscular dystrophy caused by mutations in the dystrophin } \\
\text { gene, it is possible with gene therapy to inject into muscle a functional } \\
\text { dystrophin gene. }{ }^{4} \text { The effects observed include a reduction in contraction } \\
\text { induced injury, and an increase in muscle bulk. }\end{array}$ \\
Muscular atrophy & $\begin{array}{l}\text { The National Aeronautics and Space Administration (NASA) in the United } \\
\text { States has shown that space travel can produce skeletal muscle atrophy. }\end{array}$ \\
& $\begin{array}{l}\text { Experimental studies are now underway to determine the preventive effects of } \\
\text { IGFI in a retroviral vector given regularly by intramuscular injection. }\end{array}$ \\
Rheumatoid arthritis & $\begin{array}{l}\text { Phase I studies show little toxicity when inflammatory molecules such as } \\
\text { interleukin } 1 \text { are inhibited by intra-articular injection of gene therapy } \\
\text { products. }{ }^{6}\end{array}$
\end{tabular}

are particularly useful for gene therapy, such as the capacity to permanently integrate introduced genetic sequences into the host cell genome.

Apart from viruses, there are numerous physicochemical methods for introducing DNA (or RNA) into somatic cells. The most relevant in the context of sport involves direct injection of DNA that has been formulated with a chemical carrier for more efficient uptake by cells. None of the physicochemical approaches has been successful in human trials, as the levels of gene transfer achieved are insufficient for therapeutic benefit.

The results in gene therapy have generally been disappointing despite over 1000 clinical trials since $1990 .^{1}$ Only two diseases have been successfully treated by gene therapy. Both are forms of severe combined immunodeficiency, SCID-XI and ADA-deficiency. ${ }^{23}$ Unfortunately, success has come at a cost, with three of 18 infants with SCID$\mathrm{Xl}$ treated developing leukaemia. This has now been shown to have been caused by insertional mutagenesis, which had previously been considered a remote theoretical risk associated with the integrating gene transfer technology used.

At present, there are three limitations to gene therapy: (a) gene transfer technologies are not efficient enough for most applications; $(b)$ therapeutically useful integrating gene transfer technologies carry unresolved risks; (c) there remains an inadequate understanding of the biology of therapeutically relevant target cell populations.

\section{GENE THERAPY AND SPORTING INJURIES}

There are a number of models illustrating how gene therapy may at some future time be used to treat sporting injuries (table 1).

\section{GENE DOPING IN SPORT}

Sports men and women and sporting administrators faced with the prospect of drug cheating and blood doping now need to consider gene doping. ${ }^{7}$ Although therapeutic benefit from gene therapy is difficult to achieve, gene doping is paradoxically more feasible because a very large output from the introduced gene may not be required, and the desired effect need only be short term. Regular injections at the time of sporting events may suffice. Gene doping is further simplified as it would not be necessary to have the transferred gene regulated so that its output corresponds to specific cellular requirements as might be the case for treating disease.

Genes of relevance to doping such as growth hormone, insulin-like growth factor I, and erythropoietin have been cloned, and so are readily available. They could be used as an alternative way to produce a range of performance enhancing agents. The risks of taking these substances in the form of traditional chemicals are known, and so decisions about risk versus benefit are straightforward. The same cannot be said for gene doping, as there continue to be many unknowns in this form of cellular intervention. Effects cannot be predicted, and so the sportsperson taking this route for cheating does not have control of the product. Random integration of vector sequences, for example, could produce complications such as acute leukaemia or other forms of cancer. Finally, unlike taking a drug, gene transfer is not easy to reverse, and so any untoward effects may be long term. There is also a small risk of inadvertent gene transfer to germ cells with the potential for harm to be passed on to an athlete's children.

Today, the risks for gene doping are much greater than the taking of traditional chemical products. Those involved in sport should be sufficiently informed of the risks, as well as likely future benefits of gene therapy. As the technology improves, many of the complications may be avoided, and so ongoing assessment of the potential for gene doping will be necessary. Detecting gene doping cheats will be possible using the standard assays as well as through the identification of gene vectors or their products. The bypassing of various metabolic pathways through the insertion of genes may lead to changes in gene expression profiles, and this may open up another approach to detecting gene doping.

Br J Sports Med 2006;40:4-5.

doi: $10.1136 / \mathrm{bjsm} .2005 .021709$

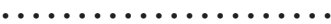

Authors' affiliations

R J Trent, Department of Molecular and Clinical Genetics, Royal Prince Alfred Hospital in the Central Clinical School, University of Sydney, NSW, Australia

I E Alexander, Gene Therapy Research Unit, The Children's Hospital, Westmead and Children's Medical Research Institute, Sydney, NSW, Australia

Correspondence to: Professor Trent, Department of Molecular and Clinical Genetics, Royal Prince Alfred Hospital in the Central Clinical School, University of Sydney, NSW 2050, Australia; rtrent@med.usyd.edu.au Competing interests: none declared

\section{REFERENCES}

1 Gene therapy clinical trials worldwide. http:// www.wiley.co.uk/genmed/clinical (accessed 19 Oct 2005).

2 Cavazzana-Calvo M, Hacein-Bey S, de Saint Basile $G$, et al. Gene therapy of human severe combined immunodeficiency (SCID)-X1 disease. Science 2000;288:669-72.

3 Aiuti A, Vai S, Mortellaro A, et al. Immune reconstitution in ADA-SCID affer PBL gene therapy and discontinuation of enzyme replacement. Nat Med 2002;8:423-5.

4 DelloRusso C, Scott JM, Hartigan-O'Connor D, et al. Functional correction of adult $\mathrm{mdx}$ mouse muscle using gutted adenoviral vectors expressing full-length dystrophin. Proc Natl Acad Sci USA 2002;99: 12979-84.

5 NASA Exploration Systems Mission Directorate Education Outreach. http://weboflife.nasa.gov/ currentResearch/currentResearchFlight/ geneTherapy.htm (accessed 19 Oct 2005).

6 Evans CH, Robbins PD, Ghivizzani SC, et al. Gene transfer to human joints: progress toward a gene therapy of arthritis. Proc Natl Acad Sci USA 2005; 102:8698-703.

7 Haisma HJ. Gene doping: a report from the Netherlands Centre for Doping Affairs. http:// www.genedoping.com (accessed 19 Oct 2005). 


\section{Research based recommendations on management of sport related concussion: summary of the National Athletic Trainers' Association position statement}

\section{K M Guskiewicz, S L Bruce, R C Cantu, M S Ferrara, J P Kelly, M McCrea, M Putukian, T C Valovich McLeod}

Sport related concussion should always be treated seriously and systematically

S port related concussion has received considerable attention in both the lay media and medical literature in recent years. As a result, clinicians, coaches, parents, and athletes at all levels of competition are becoming educated about the necessity to treat concussions seriously. In time, this will help to create a safer playing environment for athletes at all levels of competition. Despite an array of complexities associated with studying sport related concussion, new scientific research and clinically based literature have provided sports medicine professions with a wealth of updated information on the treatment of sport related concussion.

For example, there is now sufficient literature supporting the notion that once you experience a concussion, you are more likely to sustain future concussions $^{12}$; and a strong likelihood exists that the symptoms following these repeat concussions may be more serious and resolve at a slower rate. ${ }^{13}$ Several recent research papers and consensus statements indicate the necessity to use a systematic approach to evaluating the severity and duration of all possible signs and symptoms after a concussion, and to be cautious of not returning players to competition too quickly. ${ }^{4-16}$ Loss of consciousness and amnesia are two important parameters associated with cerebral concussion, but headaches, dizziness/balance deficits, concentration deficits, and feeling "slowed down" are more common. ${ }^{12} 6914$ 1720 Extensive research has also been conducted on neuropsychological testing ${ }^{17-34}$ and postural stability testing, ${ }^{20}{ }^{35-37}$ both of which are considered to be key markers for tracking recovery after cerebral concussion. Recent concussion publications on topics such as physician referral and home care, ${ }^{13} 38$ youth athletes, ${ }^{39}{ }^{40}$ and protective equipment $^{41}$ have also provided clinicians with a better understanding of how better to manage sport related concussion.

To provide certified athletic trainers professionals with a comprehensive list of recommendations for managing concussions, the National Athletic Trainers' Association (NATA) formed a committee charged with developing a research based position statement derived from these most recent studies. The recomment of concussed athletes at the youth, high school, collegiate, and elite levels. The writing committee consisted of a team doctor, a neurosurgeon, a neurologist, a neuropsychologist, and four ATCs.

The following summary includes recommendations that can be found in the full article published in the Journal of Athletic Training 2004;39:278-95. The full text and complete reference list for this peer reviewed position statement is also available at http://www.pubmedcentral. nih.gov and http://www.nata.org/ publicinformation/position.htm.

The summary statement is organised into the following sections: Defining and recognising the concussion; Evaluating and making the return to play decision; Concussion assessment tools; When to refer to a physician; When to disqualify an athlete; Special considerations for young athletes; Home care; Equipment issues.

\section{DEFINING AND RECOGNISING THE CONCUSSION}

(1) The ATC should develop a high sensitivity for the various mechanisms (ATCs), doctors, and other medical mendations are intended for the treat- and presentations of traumatic brain injury, including mild, moderate, and severe cerebral concussion, as well as the more severe but less common head injuries that can cause damage to the brain stem and other vital centres of the brain.

(2) The colloquial term "ding" should not be used to describe a sport related concussion. This stunned confusional state is a concussion most often reflected by the athlete's initial confusion, which may disappear within minutes, leaving no outward observable signs and symptoms. Use of the term "ding" generally carries a connotation that diminishes the seriousness of the injury. If an athlete shows concussionlike signs and reports symptoms after a contact to the head, the athlete has, at the very least, sustained a mild concussion and should be treated for a concussion.

(3) To detect deteriorating signs and symptoms that may indicate a more serious head injury, the ATC should be able to recognise both the obvious signs (fluctuating levels of consciousness, balance problems, memory and concentration difficulties, etc) and common self reported symptoms (headache, ringing in the ears, nausea, etc).

(4) The ATC should play an active role in educating athletes, coaches, and parents about the signs and symptoms associated with concussion, as well as the potential risks of playing while still symptomatic.

(5) The ATC should document all pertinent information surrounding the concussive injury, including, but not limited to, (a) mechanism of injury, (b) initial signs and symptoms, (c) state of consciousness, (d) findings on serial testing of symptoms, neuropsychological function, and postural stability (noting any deficits compared with baseline), (e) instructions given to the athlete and/or parent, $(f)$ recommendations provided by the physician, $(g)$ date and time of the athlete's return to participation, and $(h)$ relevant information on the player's history of prior concussion and associated recovery pattern(s).

\section{EVALUATING AND MAKING THE RETURN TO PLAY DECISION}

(6) ATCs and team physicians working together should agree on a philosophy for managing sport related concussion before the start of the athletic season. Currently three approaches are commonly used: (a) grading the concussion at the time of the injury; $(b)$ deferring final grading until all symptoms have resolved; or (c) not using a grading scale but rather focusing attention on the athlete's recovery by symptoms, 
neurocognitive testing, and postural stability testing. After deciding on an approach, the ATC-physician team should be consistent in its use regardless of the athlete, sport, or circumstances surrounding the injury.

(7) For athletes playing sports with a high risk of concussion, baseline cognitive and postural stability testing should be considered. In addition to the concussion injury assessment, the evaluation should also include an assessment of the cervical spine and cranial nerves to identify any cervical spine or vascular intracerebral injuries.

(8) The ATC should record the time of the initial injury and document serial assessments of the injured athlete, noting the presence or absence of signs and symptoms of injury. The ATC should monitor vital signs and level of consciousness every five minutes after a concussion until the athlete's condition improves. The athlete should also be monitored over the next few days after the injury for the presence of delayed signs and symptoms and to assess recovery.

(9) Concussion severity should be determined by paying close attention to the severity and persistence of all signs and symptoms, including the presence of amnesia (retrograde and anterograde) and loss of consciousness, as well as headache, concentration problems, dizziness, blurred vision, etc. It is recommended that ATCs and physicians consistently use a symptom checklist similar to the one provided in appendix A.

(10) In addition to a thorough clinical evaluation, formal cognitive and postural stability testing is recommended to assist in objectively determining injury severity and readiness to return to play. No one test should be used solely to determine recovery or return to play, as concussion presents in many different ways.

(11) Once symptom-free or asymptomatic, the athlete should be reassessed to establish that cognition and postural stability have returned to normal for that player, preferably by comparison with pre-injury baseline test results. The return to play decision should be made after an incremental increase in activity with an initial cardiovascular challenge, followed by sport specific activities that do not place the athlete at risk of concussion. The athlete can be released to full participation as long as no recurrent signs or symptoms are present.

\section{CONCUSSION ASSESSMENT TOOLS}

(12) Baseline testing on concussion assessment measures is recommended to establish the individual athlete's "normal" pre-injury performance and to provide the most reliable benchmark against which to measure recovery. Baseline testing also controls for extraneous variables (attention deficit disorder, learning disabilities, age, education, etc) and for the effects of previous concussion, while also evaluating the possible cumulative effects of recurrent concussions.

(13) The use of objective concussion assessment tools will help ATCs in more accurately identifying deficits caused by injury and recovery from injury and protect players from the potential risks associated with prematurely returning to competition and sustaining a repeat concussion. The concussion assessment battery should include a combination of tests for cognition, postural stability, and self reported symptoms known to be affected by concussion.

(14) A combination of brief screening tools appropriate for use on the sideline-for example, standardised assessment of concussion (SAC), balance error scoring system (BESS), symptom checklist-and more extensive measures-for example, neuropsychological testing, computerised balance testing-to evaluate more precisely recovery later after injury is recommended.

(15) Before instituting a concussion neuropsychological testing battery, the ATC should understand the test's user requirements, copyright restrictions, and standardised instructions for administration and scoring. All evaluators should be appropriately trained in the standardised instructions for test administration and scoring before embarking on testing or adopting an instrument for clinical use. Ideally, the sports medicine team should include a neuropsychologist, but in reality, many ATCs may not have access to a neuropsychologist for interpretation and consultation, nor the financial resources to support a neuropsychological testing program. In this case, it is recommended that the ATC use screening instruments (SAC, BESS, symptom checklist) that have been developed specifically for use by sports medicine clinicians without extensive training in psychometric or standardised testing and that do not require a special license to administer or interpret.

(16) ATCs should adopt for clinical use only, those neuropsychological and postural stability measures with population specific normative data, test-retest reliability, clinical validity, and sufficient sensitivity and specificity established in the peer reviewed literature. These standards provide the basis for how well the test can distinguish between those with and without cerebral dysfunction in order to reduce the possibility of making false positive and false negative errors, which could lead to clinical decision-making errors.

(17) As is the case with all clinical instruments, results from assessment measures to evaluate concussion should be integrated with all aspects of the injury evaluation-for example, physical examination, neurological evaluation, neuroimaging, player's history, etc-for the most effective approach to injury management and return to play decision making. Decisions about an athlete's return to play should never be based solely on the use of any one test.

\section{WHEN TO REFER TO A PHYSICIAN}

(18) The ATC or team physician should monitor an athlete with a concussion at five minute intervals from the time of the injury until the athlete's condition completely clears or the athlete is referred for further care. Coaches should be informed that in situations when a concussion is suspected but an ATC or physician is not available, their primary role is to ensure that the athlete is immediately seen by an ATC or physician.

(19) An athlete with a concussion should be referred to a physician on the day of injury if he or she lost consciousness, experienced amnesia lasting longer than 15 minutes, or meets any of the criteria outlined in appendix B.

(20) A team approach for the assessment of concussion should be used to include a variety of medical specialties. In addition to family practice or general medicine physician referrals, the ATC should secure other specialist referral sources within the community. For example, neurologists are trained to assist in the management of patients experiencing persistent signs and symptoms, including sleep disturbances. Similarly, a neuropsychologist should be identified as part of the sports medicine team for assisting athletes who require more extensive neuropsychological testing and for interpreting the results of neuropsychological tests.

(21) A team approach should be used in making return to play decisions after concussion. This approach should involve input from the ATC, physician, athlete, and any referral sources. The assessment of all information including the physical examination, imaging studies, objective tests, and exertional efforts should be considered before making a return to play decision.

\section{WHEN TO DISQUALIFY AN ATHLETE}

(22) Athletes who are symptomatic at rest and after exertion for at least 20 minutes should be disqualified from 
returning to participation on the day of the injury. Exertional exercises should include sideline jogging followed by sprinting, sit ups, push ups, and any sport specific, non-contact activities (or positions or stances) the athlete might need to perform on returning to participation. Athletes who return on the same day because symptoms resolved quickly ( $<20$ minutes) should be monitored closely after they return to play. They should be repeatedly re-evaluated on the sideline, after the practice or game, and again at 24 and 48 hours after the injury to identify any delayed onset of symptoms.

(23) Athletes who experience loss of consciousness or amnesia should be disqualified from participating on the day of the injury.

(24) The decision to disqualify from further participation on the day of a concussion should be based on a comprehensive physical examination, assessment of self reported post-concussion signs and symptoms, functional impairments, and the athlete's history of concussions. If assessment tools such as the SAC, BESS, neuropsychological test battery, and symptom checklist are not used, a seven day symptom-free waiting period before returning to participation is recommended. Some circumstances, however, will warrant even more conservative treatment (see recommendation 25 ).

(25) ATCs should be more conservative with athletes who have a history of concussion. Athletes with a history of concussion are at increased risk of sustaining subsequent injuries, as well as slow recovery of self reported postconcussion signs and symptoms, cognitive dysfunction, and postural instability after subsequent injuries. In athletes with a history of three or more concussions who are experiencing slow recovery, temporary or permanent disqualification from contact sports may be indicated.

\section{SPECIAL CONSIDERATIONS FOR YOUNG ATHLETES}

(26) ATCs working with younger (paediatric) athletes should be aware that recovery may take longer than in older athletes. In addition, these younger athletes are maturing at a relatively fast rate and will probably require more frequent updates of baseline measures compared with older athletes.

(27) Many young athletes experience sport related concussion. ATCs should play an active role in helping to educate young athletes, their parents, and coaches about the dangers of repeated concussions. Continued research into the epidemiology of sport related concussion in young athletes and prospective investigations to determine the acute and long term effects of recurrent concussion in younger athletes are warranted.

(28) Because damage to the maturing brain of a young athlete can be catastrophic (almost all reported cases of second-impact syndrome are in young athletes), younger athletes (under the age of 18 years) should be managed more conservatively, using stricter return to play guidelines than those used to manage concussion in the more mature athlete.

\section{HOME CARE}

(29) An athlete with a concussion should be instructed to avoid taking drugs except acetaminophen after the injury. Acetaminophen and other drugs should only be given at the recommendation of a physician. In addition, the athlete should be instructed to avoid ingesting alcohol, illicit drugs, or other substances that might interfere with cognitive function and neurological recovery.

(30) Any athlete with a concussion should be instructed to rest, but complete bed rest is not recommended. The athlete should resume normal activities of daily living as tolerated, while avoiding activities that potentially increase symptoms. Once he or she is asymptomatic, the athlete may resume a graded programme of physical and mental exertion, without contact or risk of concussion, up to the point at which post-concussion signs and symptoms recur. If symptoms appear, the exertion level should be scaled back to allow maximal activity without triggering symptoms.

(31) An athlete with a concussion should be instructed to eat a well balanced diet that is nutritious in both quality and quantity.

(32) An athlete should be awakened during the night to check on deteriorating signs and symptoms only if he or she experienced loss of consciousness, had prolonged periods of amnesia, or was still experiencing significant symptoms at bedtime. The purpose of the wake ups is to check for deteriorating signs and symptoms, such as decreased levels of consciousness or increasing headache, which could indicate a more serious head injury or a late onset complication such as an intracranial bleed.

(33) Oral and written instructions for home care should be given to the athlete and to a responsible adult-for example, parents or roommate-who will observe and supervise the athlete during the acute phase of the concussion while at home or in the dormitory. The ATC and physician should agree on a standard concussion home instruction form similar to the one presented in appendix C, and it should be used consistently for all concussions.

\section{EQUIPMENT ISSUES}

(34) The ATC should enforce the standard use of helmets for protecting against catastrophic head injuries and reducing the severity of cerebral concussions. In sports that require helmet protection (football, lacrosse, ice hockey, baseball/softball, etc), the ATC should ensure that all equipment meets either the National Operating Committee on Standards for Athletic Equipment (NOCSAE) or American Society for Testing and Materials (ASTM) standards.

(35) The ATC should enforce the standard use of mouthguards for protection against dental injuries, even though the scientific evidence supporting their use for reducing concussive injury is not yet convincing.

(36) At this time, the ATC should neither endorse nor discourage the use of soccer headgear for protecting against concussion or the consequences of cumulative, subconcussive impacts to the head. Currently, no scientific evidence supports the use of headgear in soccer for reducing concussive injury to the head.

Br J Sports Med 2006;40:6-10. doi: $10.1136 / \mathrm{bjsm} .2005 .021683$

\section{Authors' affiliations}

K M Guskiewicz, Department of Exercise and Sport Science, University of North Carolina at Chapel Hill, Chapel Hill, NC, USA

S L Bruce, California State University of Pennsylvania, California, PA, USA

R C Cantu, Emerson Hospital, Concord, MA, USA and Neurological Sports Injury Center, Brigham and Women's Hospital, Boston, MA, USA

M S Ferrara, Exercise and Sport Science, University of Georgia, Athens, GA, USA J P Kelly, University of Colorado School of Medicine, Denver, CO, USA

M McCrea, Waukesha Memorial Hospital, Waukesha, WI, USA

M Putukian, Princeton University, Princeton, NJ, USA

T C V McLeod, Department of Sport Health Care, Arizona School of Health Sciences, Mesa, AZ, USA

Correspondence to: Dr Guskiewicz, Department of Exercise and Sport Science, University of North Carolina at Chapel Hill, Chapel Hill, NC 27599-8700, USA; gus@ email.unc.edu

Competing interests: none declared

The authors represent the writing team of the National Athletic Trainers' Association position statement on management of sport related concussion. J Athl Train 2004;39:278-95. 


\section{Appendix A}

\section{Graded symptom checklist (GSC)}

\begin{tabular}{llllll}
\hline Symptom & $\begin{array}{l}\text { Time of } \\
\text { injury }\end{array}$ & $\begin{array}{l}2-3 \mathrm{~h} \\
\text { after injury }\end{array}$ & $\begin{array}{l}24 \mathrm{~h} \\
\text { after injury }\end{array}$ & $\begin{array}{l}48 \mathrm{~h} \\
\text { after injury }\end{array}$ & $\begin{array}{l}72 \mathrm{~h} \\
\text { after injury }\end{array}$
\end{tabular}

Blurred vision

Dizziness

Drowsiness

Excess sleep

Easily distracted

Fatigue

Feel "in a fog"

Feel "slowed down"

Headache

Inappropriate emotions

Irritability

Loss of consciousness

Loss or orientation

Memory problems

Nausea

Nervousness

Personality change

Poor balance/coord.

Poor concentration

Ringing in ears

Sadness

Seeing stars

Sensitivity to light

Sensitivity to noise

Sleep disturbance

Vacant stare/glassy eyed

Vomiting

Note: the GSC should be used not only for the initial evaluation but for each subsequent follow up assessment until all signs and symptoms have cleared at rest and during physical exertion. In lieu of simply checking each symptom present, the ATC can ask the athlete to grade or score the severity of the symptom on a scale of $0-6$, where $0=$ not present, $1=$ mild, $3=$ moderate, and $6=$ most severe.

\section{Appendix B}

Physician referral checklist

Day of injury referral

1. Loss of consciousness on the field

2. Amnesia lasting longer than 15 minutes

3. Deterioration of neurological function*

4. Decreasing level of consciousness*

5. Decrease or irregularity in respirations*

6. Decrease or irregularity in pulse*

7. Increase in blood pressure

8. Unequal, dilated, or unreactive pupils*

9. Cranial nerve deficits

10. Any signs or symptoms of associated injuries, spine or skull fracture, or bleeding*

11. Mental status changes: lethargy, difficulty maintaining arousal, confusion, agitation*

12. Seizure activity*

13. Vomiting

14. Motor deficits subsequent to initial on-field assessment

15. Sensory deficits subsequent to initial on-field assessment

16. Balance deficits subsequent to initial on-field assessment

17. Cranial nerve deficits subsequent to initial on-field assessment

18. Post-concussion symptoms that worsen

19. Additional post-concussion symptoms as compared with those on the field

20. Athlete is still symptomatic at the end of the game (especially at high school level)

Delayed referral (after the day of injury)

1. Any of the findings in the day of injury referral category

2. Post-concussion symptoms worsen or do not improve over time

3. Increase in the number of post-concussion symptoms reported

4. Post-concussion symptoms begin to interfere with the athlete's daily activities (sleep disturbances, cognitive difficulties)

*Requires the athlete be transported immediately to the nearest emergency department.

\section{REFERENCES}

1 Guskiewicz KM, McCrea M, Marshall SW, et al. Cumulative effects of recurrent concussion in collegiate football players: the NCAA Concussion Study. JAMA 2003;290:2549-55.

2 Guskiewicz KM, Weaver NL, Padua DA, et al. Epidemiology of concussion in collegiate and high school football players. Am J Sports Med 2000;28:643-50.

3 Iverson GL, Gaetz M, Lovell MR, et al. Cumulative effects of concussion in amateur athletes. Brain Injury 2004; 18:433-43.

4 Aubry M, Cantu R, Dvorak J, et al. Summary and agreement statement of the First International Conference on Concussion in Sport, Vienna
2001: recommendations for the improvement of safety and health of athletes who may suffer concussive injuries. Br J Sports Med 2002;36:6-10.

5 Bailes JE, Hudson V. Classification of sportrelated head trauma: a spectrum of mild to severe injury. J Athl Train 2001;36:236-43.

6 Cantu RC. Posttraumatic retrograde and anterograde amnesia: pathophysiology and implications in grading and safe return to play. $J$ Athl Train 2001;36:244-8

7 Giza CC, Hovda DA. The neurometabolic cascade of concussion. J Athl Train 2001;36:228-35.

8 Guskiewicz KM, Cantu RC. The concussion puzzle: evaluation of sport-related concussion. Am J Med Sports 2004;6:13-21.

9 Kelly JP. Loss of consciousness: Pathophysiology and implications in grading and safe return to play. J Athl Train 2001;36:249-52.

10 Lovell MR, Iverson GL, Collins MW, et al. Does loss of consciousness predict neuropsychological decrements after concussion? Clin J Sport Med 1999:9:193-8

11 Lovell MR, Collins MW, Iverson GL, et al. Recovery from mild concussion in high school athletes. J Neurosurg 2003;98:296-301.

12 Lovell MR, Collins MW, Iverson GL, et al. Grade 1 or "ding" concussions in high school athletes. Am J Sports Med 2004;32:47-54.

13 McCrory $\mathbf{P}$. What advice should we give to athletes postconcussion? Br J Sports Med 2002;36:316-18.

14 McCrory P, Ariens T, Berkovic SF. The nature and duration of acute concussive symptoms in Australian football. Clin J Sport Med 2000;10:235-8.

15 Oliaro S, Anderson S, Hooker D. Management of cerebral concussion in sports: the athletic trainer's perspective. J Athl Train 2001;36:257-62.

16 Practice parameter: the management of concussion in sports (summary statement) Report of the Quality Standards Subcommittee of the American Academy of Neurology. Neurology 1997:48:581-5.

17 Collins MW, Iverson GL, Lovell MR, et al. On-field predictors of neuropsychological and symptom deficit following sports-related concussion. Clin J Sport Med 2003;13:222-9.

18 Erlanger D, Kaushik T, Cantu R, et al. Symptombased assessment of the severity of a concussion. J Neurosurg 2003;98:477-84.

19 Erlanger D, Saliba E, Barth JT, et al. Monitoring resolution of postconcussion symptoms in athletes: preliminary results of a web-based neuropsychological test protocol. J Athl Train 2001;36:280-7

20 McCrea M, Guskiewicz KM, Barr W, et al. Acute effects and recovery time following concussion in collegiate football players: the NCAA Concussion Study. JAMA 2003;290:2556-63.

21 Barr WB, McCrea M. Sensitivity and specificity of standardized neurocognitive testing immediately following sports concussion. J Int Neuropsychol Soc 2001; 7:693-702.

22 Bleiberg J, Cernich AN, Cameron K, et al. Duration of cognitive impairment after sports concussion. Neurosurgery 2004;54:1073-80.

23 Collie A, Darby D, Maruff P. Computerised cognitive assessment of athletes with sports related head injury. Br J Sports Med 2001;35:297-302.

24 Collie A, Maruff P, Makdissi M, et al. CogSport: reliability and correlation with conventional cognitive tests used in postconcussion medical evaluations. Clin J Sport Med 2003;13:28-32

25 Collins MW, Field M, Lovell MR, et al. Relationship between postconcussion headache and neuropsychological test performance in high school athletes. Am J Sports Med 2003:31:168-73.

26 Collins MW, Grindel SH, Lovell MR, et al Relationship between concussion and neuropsychological performance in college football players. JAMA 1999;282:964-70.

27 Collins MW, Lovell MR, Iverson GL, et al. Cumulative effects of concussion in high school athletes. Neurosurgery 2002;51:1175-81.

28 Daniel JC, Olesniewicz MH, Reeves DL, et al. Repeated measures of cognitive processing 


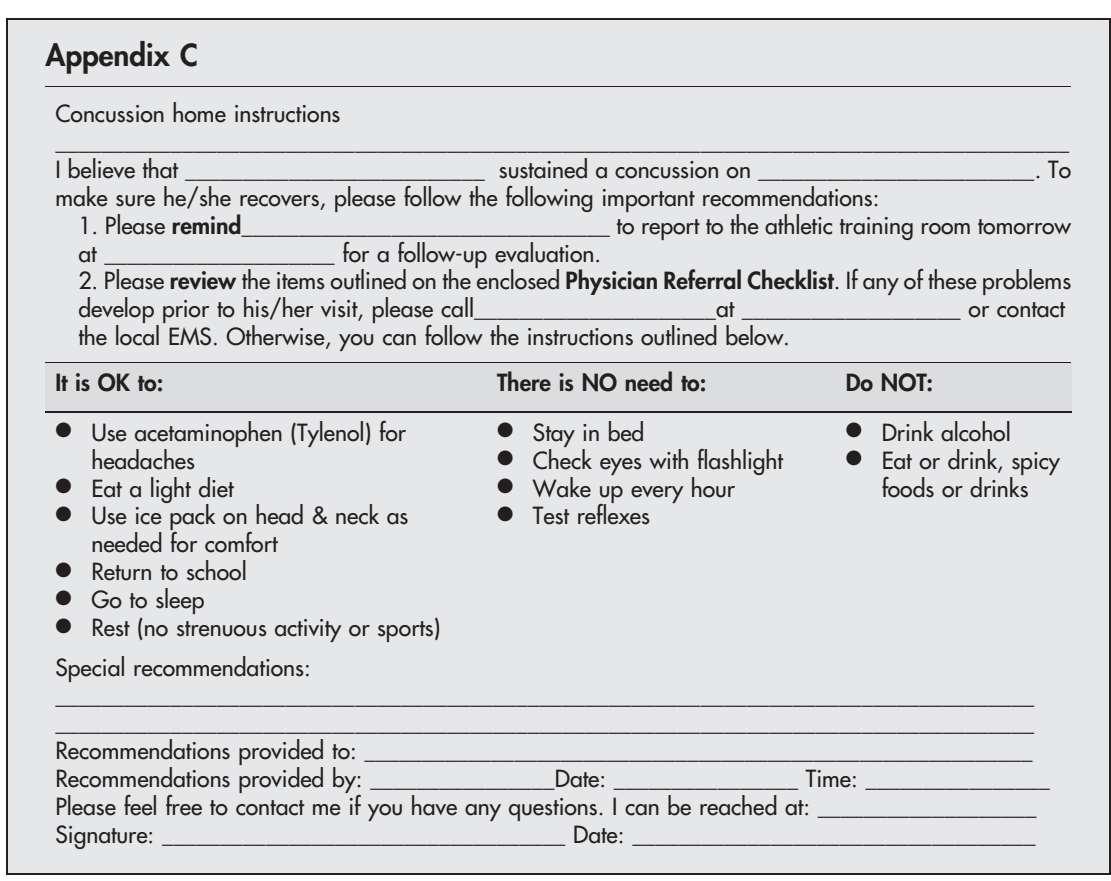

efficiency in adolescent athletes: implications for monitoring recovery from concussion.

Neuropsychiatry Neuropsychol Behav Neurol 1999; 12:167-9.

29 Echemendia R, Putukian M, Mackin RS, et al.

Neuropsychological test performance prior to and following sports-related mild traumatic brain injury. Clin J Sport Med 2001:11:23-31.

30 Makdissi M, Collie A, Maruff P, et al. Computerised cognitive assessment of concussed Australian Rules footballers. Br J Sports Med 2001;35:354-60.
31 McCrea M. Standardized mental status assessment of sports concussion. Clin J Sport Med 2001;11:176-81.

$32 \mathrm{McCrea} M$. Standardized mental status testing on the sideline after sport-related concussion. J Athl Train 2001;36:274-9.

33 McCrea M, Kelly JP, Randolph C, et al. Immediate neurocognitive effects of concussion. Neurosurgery 2002;50:1032-42.

34 Pottinger L, Cullum M, Stallings RL. Cognitive recovery following concussion in high school athletes. Arch Clin Neuropsychol 1999:14:39-40.

35 Guskiewicz KM, Ross SE, Marshall SW. Postural stability and neuropsychological deficits after concussion in collegiate athletes. J Athl Train 2001;36:263-73.

36 Peterson CL, Ferrara MS, Mrazik M, et al. An analysis of domain score and posturography following cerebral concussion. Clin J Sport Med 2003; 13:230-7.

37 Riemann BL, Guskiewicz KM. Effects of mild head injury on postural stability as measured through clinical balance testing. $J$ Athl Train 2000;35:19-25

38 de Kruijk JR, Leffers P, Meerhoff S, et al. Effectiveness of bed rest after mild traumatic brain injury: a randomised trial of no versus six days of bed rest. J Neurol Neurosurg Psychiatry 2002;73:167-72.

39 Adams J, Frumiento C, Shatney-Leach L, et al. Mandatory admission after isolated mild closed head injury in children: is it necessary? J Pediatr Surg 2001;36:119-21.

40 Field $M$, Collins MW, Lovell MR. Does age play a role in recovery from sports related concussion? A comparison of high school school and collegiate athletes. Am J Pediatr 2003; 142:546-53.

41 Halstead DP. Performance testing updates in head, face, and eye protection. J Athl Train 2001;36:322-7.

\section{1 th European Forum on Quality Improvement in Health Care}

26-28 April 2006, Prague, Czech Republic

For further information please go to: www.quality.bmipg.com

Book early to benefit from a discounted delegate rate 